\title{
Revisión: El queso de Tafí del Valle y el despertar de la cultura del queso en Argentina
}

\author{
Review: Cheese Tafi del Valle and the awakening of the culture \\ of cheese in Argentina
}

Pablo Lacoste 1

\section{RESUMEN}

Este artículo examina la génesis, identidad y evolución del queso de Tafí del Valle (Tucumán, Argentina). Se detecta que en sus orígenes era un queso curado de montaña, elaborado con leches de vaca, oveja y/o ambas; luego se desarrolló una variedad condimentada con ají. En el siglo XIX se posicionó como producto de calidad en los mercados rioplatenses y llegó a la mesa presidencial. Se concluye que este fue el primer queso típico de origen de la Argentina y, junto con el queso de Chanco (Chile), lideró la cultura quesera en el Cono Sur de América.

Palabras clave: queso de Tafí del Valle, cultura quesera latinoamericana, productos típicos, denominaciones de origen.

\section{ABSTRACT}

This article examines the genesis, identity and evolution cheese Tafi del Valle (Tucuman, Argentina). Originally it was a mountain cured cheese, made with milk from cows, sheep and-or both; then a variety spiced with chili developed. In the nineteenth century it was positioned as a quality product in the River Plate markets and arrived at the presidential table. It is concluded that this was the first typical cheese origin of Argentina and, together with cheese Chanco (Chile), led the cheese-making culture in the Southern Cone of America.

Key words: cheese Tafi del Valle, Latin American cheesemaking culture, typical products, designations of origin.

\section{Introducción}

El queso de Tafí del Valle, junto con el queso de Goya y el queso de Chanco, conforman la tríada de quesos históricos del cono sur de América. Ambos se originaron en lugares precisos: el primero, en las montañas del Tucumán; el segundo, junto al río Paraná, en Corrientes (Balmaceda, 2016) y; el tercero, en el secano costero e interior del Valle Central, en Chile (Aguilera, 2016; Lacoste et al., 2014 y 2015).

Nacidos en el siglo XVIII, los quesos del Tafí, Goya y Chanco forman parte del selecto club de productos típicos latinoamericanos con cerca de trescientos años de historia junto al tequila mexicano (Hernández, 2013), el pajarete del Huasco (Castro et al., 2016), el pisco de Perú y Chile (Cofré et al.,
2016, Lacoste et al., 2016), la chicha y sidra de manzana (Castro et al., 2016) entre otros pocos.

El estudio del origen, naturaleza y evolución de estos productos representa, por o tanto, un aporte al fortalecimiento de la identidad de los productos típicos y la gastronomía de América Latina.

Tafí del Valle se encuentra en el corazón de los Andes, $100 \mathrm{~km}$ al oeste de la ciudad de Tucumán. Se trata de un valle fértil y pintoresco, situado a 2.000 metros de altitud, flanqueado al norte por los montes Calchaquíes y al sur por la sierra del Aconquija, cuyas cimas superan los 5.600 metros snm. Numerosos ríos, arroyos y lagunas terminan de configurar un territorio de difícil acceso y singular belleza escénica.

Los orígenes del queso de Tafí del Valle se remontan a la época colonial, cuando los jesuitas

\footnotetext{
1 Universidad de Santiago de Chile. Santiago, Chile.

* Autor por correspondencia: pablo.lacoste@usach.cl
} 
comenzaron a elaborar estos quesos, en la hacienda que poseían en las montañas del Tucumán. El carácter inaccesible del lugar de producción tuvo dos efectos: limitó las dimensiones de su desarrollo y preservó su identidad durante tres siglos. Esta situación varió a fines del siglo XX, con la construcción de carreteras y la conexión de Tafí del Valle con los modernos medios de transporte. Recién entonces se removieron los obstáculos para el mayor conocimiento de la zona y sus atractivos turísticos y gastronómicos. En 1970 se comenzó a celebrar la Fiesta Nacional del Queso, tradición que se ha mantenido vigente hasta la actualidad (en 2017 se celebró la 48 edición). Las antiguas construcciones jesuitas se reconocieron y protegieron como patrimonio histórico; mejoraron también las inversiones en instalaciones y equipamiento, con lo que, se terminó por configurar un atractivo polo de actividad turística y agroindustrial.

El queso de Tafí del Valle se menciona en la literatura especializada. Los agentes diplomáticos ingleses han registrado su existencia (Parish, 1852). Además, figura en obras dedicadas a la labor de los jesuitas en la zona (Peña de Bascary, 1986; Furlong, 1994) y a la gastronomía nacional (Silveira, 2005; Prestigiacomo y Uccello, 2014; Balmaceda, 2016). Estos autores apenas mencionan al queso de Tafí del Valle en algunas líneas, sin profundizar en el tema. Esta situación contrasta con los otros dos quesos históricos, que sí han merecido mayor desarrollo. Por ejemplo, en su libro sobre "La comida en la historia argentina", se dedica un capítulo al queso de Goya, desde sus orígenes, en la casa de Gregoria Morales, en un ignoto pueblito junto al río Paraná, $220 \mathrm{~km}$ al sur de Corrientes, a fines del siglo XVIII. La calidad de estos quesos hizo crecer rápido su prestigio y su demanda, sobre todo en Buenos Aires. La maestra quesera, doña Gregoria, llamada popularmente "Goya", terminó por imponer su nombre al queso y a la ciudad. De este modo, según el autor, el queso de Goya se convirtió en "el primero con sello de origen argentino" (Balmaceda, 2016).

Los trabajos citados representan un punto de partida interesante para avanzar en la investigación. El presente artículo propone profundizar en el conocimiento del origen y la identidad del queso de Tafí del Valle, en el contexto de la cultura ganadera y quesera de la región. Se trata de sistematizar la información disponible, a la luz de su contexto sociocultural, y con la incorporación de otras fuentes, hasta ahora no consideradas por los especialistas, particularmente la correspondencia entre el presidente Sarmiento y su amigo tucumano José Posse, la que forma un corpus documental de doce epístolas con referencias concretas al queso de Tafí del Valle.

\section{Ganadería y cultura del queso en el espacio rioplatense}

El queso es parte de la industria láctea que, a su vez, se encuadra dentro de un movimiento mayor, formado por la historia de la ganadería y sus derivados. Los conquistadores españoles introdujeron los bovinos, equinos y ovinos en el cono sur de América en el siglo XVI y, poco a poco, la ganadería comenzó a progresar, según las condiciones de climas y suelos de cada región. Un ambiente particularmente favorable para la ganadería se dio en el espacio rioplatense-pampeano, donde la fertilidad de las pasturas naturales, facilitó la reproducción del ganado; en pocos años, millones de cabezas hicieron de Buenos Aires un polo de referencia ganadero de nivel mundial. Los cueros y la carne salada se convirtieron en los principales productos de exportación bonaerense desde comienzos del siglo XVII hasta el segundo tercio del XIX (Giberti, 1985; Montoya, 2012). La sobreabundancia de carne generó un contexto que tendía a desalentar el desarrollo de productos agroindustriales de mayor complejidad y valor agregado.

Junto con la renta ganadera primaria, otro factor que retrasó la cultura quesera en la región fue el hábito alimentario. La población rioplatense centraba su dieta en la carne, acompañada con vino de Mendoza, aguardiente de San Juan y yerba mate del Paraguay. Ocasionalmente se gustaban como postre algunas frutas secas o deshidratadas de origen cuyano. En este contexto de cultura gastronómica, el queso no tenía lugar de importancia.

Como resultado, la elaboración de quesos fue casi irrelevante en el espacio rioplatense durante el período colonial y buena parte del siglo XIX. En los inventarios de pulperías realizados por Carlos Mayo, los quesos son productos muy escasos. En los inventarios de 38 pulperías de Buenos Aires, registradas entre 1758 y 1824 , solo se detectaron siete quesos: dos quesos de la tierra, dos quesos de Maldonado y un queso de vaca (Mayo, 2000). En 
las pulperías rurales la presencia de este producto era todavía menor: solo se registraron dos casos, uno en 1782 y otro en 1808 (Mayo, 2000).

Los testimonios de los viajeros extranjeros coinciden en registrar el queso como producto excepcional en la gastronomía rioplatensepampeana. Según Caldcleugh (1825), cada casa tenía una vaca pero este "la ordeña solo lo necesario para consumo familiar, pero no hay hábito de elaborar queso ni leche" (Caldcleugh, 1825). La falta de interés y de cultura del trabajo entre los gauchos, fue detectada también por otros viajeros como muestra el siguiente testimonio:

"Es cierto que el gaucho vive sin lujos, pero el gran rasgo de su carácter es su falta de necesidades: constantemente acostumbrado a vivir al aire libre y dormir en el suelo, no considera que agujero más o menos en el rancho lo prive de comodidad. No es que no le guste el sabor de la leche, pero prefiere pasarse sin ella antes que realizar la tarea cotidiana de ir a buscarla. Es cierto que podría hacer queso y venderlo por dinero, pero si ha conseguido recado y buenas espuelas, no considera que el dinero tenga mucho valor" (Head, 1826).

Ambos autores coincidían en destacar la inconsistencia entre recursos y cultura del trabajo. Las pampas rioplatenses tenían medios abundantes para elaborar productos y subproductos con valor agregado, como el queso. Sin embargo, había limitaciones culturales infranqueables en aquel momento, que impedían realizar el potencial de la riqueza local.

Los viajeros europeos estaban muy sensibilizados con los quesos, productos relativamente corrientes en Europa. Por eso estaban atentos a detectar su presencia. Y cuando tenían la oportunidad de obtenerlo, el hecho se transformaba en acontecimiento, digno de ser incluido en sus crónicas. El episodio de Head en San Luis es elocuente al respecto (Head, 1826). La generosa aldeana le ofreció lo mejor que tenía en su casa al visitante herido: un enorme queso. Pero era un objeto aislado, sin el entorno que normalmente un europeo esperaba, para poder gustar adecuadamente ese alimento: recipientes para sostenerlo, cuchillo para cortarlo, pan y vino para el maridaje gastronómico, entre otros detalles. Nada de eso tenía la posada de San Luis, aquella noche de 1824.

Los quesos que había en el espacio rioplatensepampeano eran escasos y por lo tanto, de alto precio. Al menos así lo apreciaban los viajeros europeos, tras comparar los precios de los alimentos locales con los vigentes entonces en el viejo conteniente. En efecto, la carne, el vino, el aguardiente y los duraznos eran baratos; pero otros alimentos eran más caros que en Europa, particularmente el queso (Beaumont, 1828).

La abundancia de ganado, tanto vacuno como ovino, generaba las condiciones para el surgimiento de una dinámica producción quesera en la región. Por eso, los viajeros europeos se asombraban al comprobar la escasa presencia de estos productos en el mercado rioplatense. Este concepto fue compartido por un intelectual criollo, Domingo Faustino Sarmiento.

\section{Sarmiento y la construcción de la cultura del queso en Argentina}

Gobernador de San Juan, presidente de Argentina, varias veces parlamentario, ministro y general, periodista y ensayista, Domingo Faustino Sarmiento fue uno de los más destacados intelectuales y estadistas latinoamericanos del siglo XIX. La fecundidad de sus artículos, discursos y libros se plasman en las 53 tomos de sus Obras Completas (Sarmiento, 2001) en las que la cultura del queso ocupa un papel relevante.

A lo largo de su extensa obra, Sarmiento dedicó un espacio relevante a la importancia de la producción quesera como herramienta de desarrollo económico y progreso social. En su ensayo Facundo (1845) Sarmiento destacaba el potencial que tenía la producción de quesos como herramienta de progreso económico y ascenso social. Como ejemplo, citaba el caso de los colonos alemanes y escoceses del sur de Buenos Aires: "Ordeñando vacas, fabricando mantequilla y quesos han logrado algunas familias hacer fortunas colosales y retirarse a la ciudad a gozar de las comodidades" (Sarmiento, 2001). Más adelante, agrega: "Las mujeres (alemanas o escocesas) guardan la casa, preparan la comida, trasquilan las ovejas, ordeñan las vacas, fabrican los quesos, y tejen las groseras telas de que se visten" (Sarmiento, 2001).

Para Sarmiento, la elaboración de quesos tenía también implicancias políticas. Sobre todo 
porque, al arraigar a la población campesina en actividades productivas, disminuía la tendencia a sumarse a montoneras, insurgencias y golpes de Estado que prolongaban la anarquía y las guerras civiles en América Latina: "La Colonia escocesa que Rivadavia fundó al sud de Buenos-Aires lo prueba hasta la evidencia; ha sufrido de la guerra, pero ella jamás ha tomado parte, y ningún gaucho alemán ha abandonado su trabajo, su lechería o su fábrica de quesos para ir a corretear por la Pampa" (Sarmiento, 2001).

Desde el punto de vista de la generación de riqueza nacional, para Sarmiento era más importante la capacidad de añadir valor que la mera disponibilidad de materias primas. Como ejemplo citaba el caso de Francia, donde la cantidad de ganado disponible era menor; pero gracias a la elaboración de subproductos, particularmente quesos, se multiplicaba la riqueza y la prosperidad nacionales. "La Francia es el país que en Europa contiene menos ganado vacuno relativamente a la población, pues hay solo 29 cabezas por cada 100 habitantes, mientras que en Dinamarca hay 100 cabezas por cada 100 habitantes, en Suiza 85, en Escocia 72, en Lombardía 50, etc., debiendo añadirse que 5.500.000 de vacas que hay en Francia, producen unas con otras, en leche, quesos, mantequilla, etc., la friolera de unos mil millones de pesos fuertes al año, cantidad que no vale todo el ganado de Buenos Aires, inclusos los caballos y los bípedos que los cuidan" (Sarmiento, 2001). La misma clave encontraba en la prosperidad de New York. Para Sarmiento, para convertirse en emporio comercial, esta localidad había montado un mecanismo productivo, en el que se incluía el esfuerzo por añadir valor a los productos primarios del campo, incluyendo la elaboración de 50 millones de libras de queso (Sarmiento, 2001).

Los ejemplos eran recurrentes; además de mencionar los casos de Francia y Nueva York, Sarmiento encontraba otros casos para mostrar el papel de la producción de quesos en la generación de riqueza y prosperidad. En otra obra citó el caso del Estado de Illinois, que hacia 1830 generaba quesos por valor de dos millones de libras esterlinas. Para Sarmiento, estos resultados se lograban gracias a una política pública orientada a promover la cultura del trabajo por medio de la educación. Para este autor, las escuelas eran la "base de la prosperidad y de la república en EE.UU.” (Sarmiento, 2001).
La conexión entre la cultura del queso y el desarrollo económico y social se lograrán mediante el sistema educativo. Esta fue una idea, fuerza en Sarmiento, y se expresó en otras obras. Por ejemplo, en su libro De la Instrucción Popular (1849), Sarmiento destacó el papel civilizador de la Escuela Normal de Versalles, en el que se incluía la enseñanza de "proceder para la fabricación de queso, salazón, diferentes especias de queso $\mathrm{y}$ asociaciones para las diferentes especies de queso" (Sarmiento, 2001). Hacia el final de su vida, Sarmiento trató de sintetizar los conceptos claves de su mensaje, y volvió a destacar la cultura de la elaboración del queso como un síntoma de progreso social (Sarmiento, 2001). Al realizarse el balance del papel del queso en la obra general del estadista, resulta notable la diversidad de funciones que Sarmiento descubrió en este producto, no solo como parte de la agricultura, sino también de la educación, la política, la económica y la vida social.

\section{El queso de Tafí del Valle: Origen y evolución}

El queso de Tafí del Valle surgió, precisamente, en el marco de esta temprana tradición quesera de la mitad norte del Virreinato del Río de la Plata. En la provincia de Salta del Tucumán, particularmente en el valle del Tafí, la producción de quesos surgió asociada a las misiones jesuitas. Poco a poco, su fama se propagó por todo el territorio rioplatense. Fue celebrado por observadores británicos primero y cronistas criollos después. Más adelante, el Sarmiento lo instaló en el centro de la mesa presidencial.

El queso de Tafí surgió como producto artesanal elaborado en una localidad de la provincia de Tucumán. Todavía no se dispone de estudios monográficos específicos sobre el tema, pero la tradición tiende a asociar este producto con la tradición ganadera impulsada por los jesuitas desde el siglo XVIII. En efecto, la literatura especializada señala que dentro de la órbita del Colegio de Tucumán, los jesuitas desarrollaron la estancia de Tafí del Valle.

El valle fue colonizado tempranamente por los pueblos indígenas. Al llegar los españoles, a mediados del siglo XVI, se vieron atraídos por su pintoresca belleza y su microclima. Sin embargo, la resistencia de los pueblos diaguitas allí instalados, frustró los primeros intentos de conquista. La colonización europea se consolidó 
recién en el siglo XVII, con la distribución de mercedes reales y la compra por parte de los jesuitas. En los primeros años el proceso fue muy lento, debido a las dificultades de acceso. Pero en la centuria siguiente, se consolidó la presencia hispanocriolla en el lugar, particularmente por la acción de los padres de la Compañía. Los jesuitas levantaron allí una capilla (1718) y un dinámico emprendimiento ganadero formado por vacunos, equinos y ovinos; para añadir valor a las materias primas, se impulsó la elaboración de subproductos, incluyendo quesos. "Procúrese entablar bien la quesería”, ordenó entonces el Provincial, al realizar su visita al Colegio de Tucumán, del que dependía Tafí del Valle (Furlong, 1994).

La estancia de Tafí del Valle progresó durante la administración jesuita. Se levantó allí una casa principal, con una oficina y seis aposentos, También se construyó una iglesia con su sacristía, ornamentos y vestiduras sagradas. La crianza de ganado alcanzó niveles considerables. En los inventarios levantados en 1767, con motivo de la expulsión de los jesuitas, la hacienda del Tafí tenía entre 12.000 y 14.000 cabezas de ganado vacuno, 4.417 equinos y 2.144 ovinos (Peña de Bascary, 1986 p. 95). La Estancia de Tafí se tasó en $\$ 40.000$, lo que representaba una fortuna para le época. El monto incluía terrenos (\$12.000), construcciones (\$3.000) y ganado (\$25.000) (Maeder, 2000: 136-137). Poco después en 1774 al venderse esta propiedad se volvió a realizar un inventario, en la que figura expresamente "la quesería" (Peña de Bascary, 1986).

¿Cómo era el original queso de Tafí del Valle? Las fuentes no entregan datos explícitos sobre la naturaleza de estos quesos, al menos para el siglo XVIII. Pero se entregan indicios importantes, al señalar las especias de ganado que allí se criaban. Por lo tanto, el queso de Tafí del Valle original se elaboraba con leche de vaca, de oveja o mezcla de ambas. Además, las dificultades del camino para llegar a su mercado más cercano (ciudad de Tucumán), determinaba que no podía tratarse de un quesillo rápido, para consumo en el día; al contrario, las 20 leguas de tortuoso viaje de montaña, determinaba que el queso de Tafí del Valle debía ser, necesariamente, un queso curado, capaz de preservar su calidad durante largos días.

Los quesos de Tafí del Valle no alcanzaron cantidades importantes debido a la ausencia de medios de transportes adecuados. Esto marcó una diferencia con los quesos de Chanco, elaborados en el secano costero e interior del Valle Central chileno por medio de medios de transportes fluviales, marítimos y terrestres. Los ríos Loncomilla y Maule facilitaron la salida de los quesos de Chanco desde la zona de producción hacia el puerto de Nueva Bilbao (luego llamado Constitución) y desde allí, a los mercados de ultramar (Maino, 1990). La disponibilidad de estos medios de transportes facilitó la exportación de los quesos de Chanco hacia Buenos Aires, Valparaíso, Callao, Guayaquil y hasta California (Aguilera, 2016). En cambio, la producción quesera de Tafí del Valle, engastada en el corazón de las montañas, no tuvo acceso fácil a los mercados. Al contrario, para llegar a la ciudad de San Miguel de Tucumán, se necesitaba realizar un viaje de más de 20 leguas por caminos de montaña. Los arrieros podían completar el trayecto, pero con mucho riesgo y esfuerzo. Los fletes eran muy altos, lo que encarecía el precio final del producto. Los quesos de Tafí del Valle no formaron parte de la corriente principal de la actividad económica tucumana. Así se refleja en las obras clásicas dedicadas al funcionamiento productivo y comercial de esta región (Acevedo. 1965; Bazán, 1995). El comercio de mulas, la fabricación de carretas, los tejidos de lana (sobre todo ponchos), la elaboración de vinos, aguardientes, algodón, madera, miel, jabón y añil fueron notablemente más relevantes. Tampoco surgió un mercado interno local de importancia, orientado al consumo de los quesos de Tafí del Valle. De todos modos, surgió un pequeño nicho especializado, sobre todo en mercados externos, como se refleja en los estudios sobre el comercio exterior de la gobernación del Tucumán a fines del siglo XVIII. En efecto, San Miguel de Tucumán, principal plaza de la Intendencia de Salta, consumía productos importados de Perú, Brasil, Paraguay, Chile y otros mercados, por valor de $\$ 4.000$. " $\mathrm{La}$ mitad de esa suma se pagaba con sebo, grasa, carne, mantas y quesos" (Acevedo, 1965). Al parecer, los quesos de Tafí del Valle comenzaron tempranamente a definirse como un nicho de producto especialmente valorado, sobre todo por los mercados externos.

La Independencia facilitó la proyección nacional del queso de Tafí del Valle, sobre todo porque Tucumán se convirtió en capital nacional durante casi un año (marzo 1816/ enero 1817). Allí se reunieron las élites políticas, militares, 
económicas y sociales, en torno al "Congreso de Tucumán”, el cual declaró la independencia ( 9 de julio de 1816). Se construyó así un gran escenario para exhibir los productos típicos regionales, entre ellos, el queso de Tafí del Valle. Las élites nacionales tuvieron oportunidad de conocerlo y apreciarlo durante su estadía en Tucumán. Posteriormente, al volver a sus ciudades de origen, llevaron con ellos la cultura de la apreciación de este queso. Como resultado, el queso de Tafí del Valle se proyectó a todo el país, particularmente a Buenos Aires.

El testimonio de Parish es significativo por la alta posición que ocupó en la política regional en las décadas de 1820 y 1830 . En efecto, se desempeñó como cónsul general y encargado de negocios, para representar al gobierno británico en el Río de la Plata, entre 1824 y 1832. Junto con su tarea diplomática, se interesó por conocer la vida cultural, social y económica del país. Cumplida su misión, regresó a sus tierras donde acopió otros antecedentes para completar sus impresiones personales y como resultado, elaboró un enjundioso libro, titulado Buenos Aires y las provincias del Río de la Plata, singularmente valorado como base para el estudio de Argentina en la primera mitad del siglo XIX. Precisamente, en el marco de esta clásica obra, en el capítulo dedicado a la economía de la provincia de Tucumán, Parish destaca "sus quesos conocidos por de Tafí, que se consideran en Buenos Aires como un sabroso manjar" (Parish, 1852).

El interés del cónsul británico por el queso de Tafí del Valle inspiró a otros intelectuales a profundizar la información sobre el tema. Particularmente a Justo Maesto, el que realizó la traducción del original en inglés del texto de Parish, y le añadió notas que servían para ampliar la información. Y justamente, el queso de Tafí del Valle fue uno de los temas en los que Maesto pudo avanzar.

"Los verdaderos quesos de Tafí (que es un hermoso valle, formado por dos ásperas serranías que corren paralelas de noroeste a sudoeste) son pocos, pues no hay allí sino dos grandes estancias donde elaboran exquisitamente, llamadas la de la Laguna y la de la Silva. En ambas se harán poco más o menos de 7 a 8.000 arrobas anuales que se traen a Buenos Aires. Su precio por mayor, en Tucumán, es 2 pesos fuertes la arroba, vendiéndose a 3 al menudeo. Como sucede en Europa con el afamado queso de Flandes, también el de Tafí tiene sus adulteraciones, pues la mayor parte de los que aquí traen son elaborados en otros puntos de la provincia, y aun en las de Santiago y Salta, que son muy buenos" (Parish, 1852).

Resulta notable el reconocimiento alcanzado por el queso de Tafí del Valle en las elites regionales en el primer tercio del siglo XIX. Las notas de Maesto en el libro del cónsul británico aportan datos precisos, incluyendo cantidades y precios al detalle. El queso de Tafí del Valle tenía ya todas las características propias de los productos típicos de origen. En primer lugar, se destaca su localización geográfica: el Valle del Tafí, en las montañas tucumanas; segundo, su fama era importante, sobre todo en Buenos Aires, lugar donde la presencia de la incipiente burguesía comercial generaba un mercado de productos de calidad superior; tercero, esa fama generaba imitaciones por parte de los comerciantes que trataban de lucrar con el prestigio construido por los campesinos del lugar de origen.

Es significativo que el primer escritor interesado en poner en foco el queso de Tafí del Valle haya sido un diplomático británico. Su pluma representaba la visión de un personaje cultivado en Europa, donde ya estaba instalada la cultura de la apreciación de los vinos y alimentos especiales. Por eso, Parish contaba con herramientas culturales para identificar y comunicar la relevancia de un producto típico con origen.

La visión del ministro británico se integraba a las sensibilidades de las elites rioplatenses. Otros testimonios coinciden en destacar la relevancia que alcanzó el queso de Tafí del Valle en la gastronomía nacional. Así lo ha referido Lucio V, Mansilla, privilegiado espectador de la vida y costumbres argentinas en la época. Al referirse a las comidas, el citado autor menciona "quesillos y quesos siendo los más reputados de Goya y Tafí, y los de Holanda, genuinos entonces" (Prestigiacomo y Uccello, 2014). Más elocuente todavía es el testimonio de Sarmiento, expresado en su correspondencia.

\section{Sarmiento y el queso de Tafí del Valle}

Además de promover la elaboración de quesos en el cono sur de América, Sarmiento se interesó 
particularmente por los quesos de Tafí del Valle. En realidad, su papel en este tema fue parte de su tendencia general de valorar, alentar, promover y disfrutar los productos típicos regionales, incluyendo también los vinos de Mendoza y San Juan; las frutas, pasas y uva en fresco, entre otros bienes. En el caso particular del queso de Tafí del Valle, la valoración de Sarmiento se reflejó por medio de una serie de cartas escritas a su confidente y amigo, José Posse, con el que Sarmiento había anudado una estrecha relación durante los años en Chile. Tras la caída de Rosas, ambos fueron convocados para ocupar cargos de responsabilidad en organismos del Estado argentino. Mientras Sarmiento fue gobernador de San Juan, Posse ocupó ese mismo cargo en Tucumán. Luego, Sarmiento fue embajador, presidente, senador nacional y ministro; Posse no alcanzó cargos tan relevantes, pero se mantuvo en espacios de influencia dentro de Tucumán, lo que le permitía conseguir los quesos favoritos de su amigo y mandarlos a sus lugares de residencia.

En la correspondencia que ambos intercambiaron durante más de veinte años, las referencias al queso del Tafí eran recurrentes. Se trata de un corpus documental de doce cartas, intercambiadas entre 1855 y 1876 . Allí de entregan datos relevantes sobre calidad, precio, envases, sistemas de transporte, entre otros detalles del producto. Estos documentos constituyen una fuente valiosa porque es uno de los pocos casos detectados hasta ahora, en los que un jefe de Estado de un país latinoamericano, dedica sus líneas para expresar su valoración de un producto típico en fecha tan temprana.

A partir de esa información, se han podido reconstruir algunas características de ese producto. El queso de Tafí era un producto escogido, elaborado mediante un lento proceso de maduración, envasado en recipientes de lata, y de alto valor de mercado: en 1855 se valuaba a \$3. En algunos casos se condimentaba con ají. Se trataba de un producto escogido y artesanal, que no se distribuía en las redes regulares del comercio. Solo podía adquirirse en el lugar de producción, no así en los mercados de Buenos Aires ni en Cuyo. La única forma de acceder era por medio de amigos tucumanos que pudieran adquirirlos y enviarlos. "Tengo café para mandarte, quesos ¿pero con quién?”, escribió Posse a Sarmiento, entonces gobernador de San Juan, el 23 de agosto de 1862. Era necesario un envío especial, aprovechando las redes familiares. "Mi hermano político don Domingo Palacio debe remitirte dos quesos de Tafí forrados en lata", le indicó Posse el 1 de agosto de 1861.

Los productores de quesos del Tafí, celosos custodios de la calidad, se aseguraban de completar los ciclos de maduración, aunque ello implicara frustrar los deseos de los más encumbrados personales de la elite política nacional, como el gobernador Posse y el entonces presidente Sarmiento. "Los quesos de Tafí te irán oportunamente, allá por abril, que es la estación en que se hacen buenos", escribió Posse a Sarmiento el 11 de enero de 1871. Ante la insistencia de Sarmiento, Posse intentó acortar el tiempo de espera, sin éxito. El 24 de febrero escribió: "Los quesos de Tafí ya están madurando. En el mes venidero los tendrás en tu mesa". De todos modos, este intento prematuro no se pudo cumplir y fue necesario esperar un tiempo más largo que el previsto originalmente para cumplir la promesa. Recién el 11 de julio, Posse pudo dar la buena nueva a su amigo y mandarle los quesos a Buenos Aires: "Junto con esta carta te serán entregados dos quesos de Tafí, forrados en lata, que te mando por conducto de mi yerno Ledesma. Que te salgan buenos y que los devores en buena compañía. Alcáncele una tajada al doctor Vélez".

Sarmiento valoraba enormemente el queso del Tafí y expresaba su gratitud con elocuencia, cada vez que su amigo la mandaba una provisión a Buenos Aires. El 20 de julio de 1876 Sarmiento, entonces senador de la nación, le escribió:

\footnotetext{
"Rendidas gracias por el queso con ají. Son admirables los dichos quesos con ají, o sin él, con requisición o sin ella. Cuando recibo uno de estos emisarios de Tucumán, y expresión genuina de tu cariño, me abstengo de darte las gracias con encarecimiento, por miedo de que la oposición me atribuya el torcido propósito de inducirte a mandarme otro. Pero como me anuncias uno en camino, sin esperar a que el ferrocarril llegue a tus puertas, no puedo contener por más tiempo los impulsos entusiastas de la gratitud de mi estómago, que aplaude, haciéndose (como tú lo experimentabas con las empanadas de San Juan), haciéndose agua la boca! Con tal exordio, ya no puedo recoger mi espíritu. Con ají o sin ella, los quesos de Tafí son apetecibles (la Barra aplausos frenéticos). Y... manda el otro queso que aguardan con decisión".
} 
La capacidad de apreciación del queso que Sarmiento desplegaba en estas líneas, contrasta con el talante severo y luchador que lo caracterizaba. Al parecer, la gastronomía tenía la capacidad de conectarlo con un ambiente lúdico y confortable, que se destacaba en palabras de afecto y elocuencia. Sarmiento experimentaba un grato momento cuando podía gozar del queso de Tafí; para prolongar el placer, solía dilatar el consumo, lo que, a veces, llegaba al extremo de sobrepasar la fecha de vencimiento del producto. "No sé si te he escrito que recibí los quesos y uno era exquisito; y el otro... a fuerza de mezquinarlo se desmejoró", escribió el presidente Sarmiento a José Posse el 9 de noviembre de 1871 (Sarmiento, 2001).

El queso del Tafí tuvo un peso relevante en la vida personal del estadista argentino, así como la elaboración de quesos formaba parte de su estrategia de desarrollo económico y social. Para Sarmiento, su vida privada y su vida pública se articulaban en un todo coherente. En cierto modo, al apreciar los quesos de Tafí del Valle, Sarmiento mandaba un mensaje de reconocimiento y admiración a todos los campesinos de América Latina.

\section{Conclusión}

El queso de Tafí del Valle ha logrado sostener una tradición de tres siglos de elaboración, desde su escondite, en el corazón de la cordillera de los Andes. Desde sus orígenes en el siglo XVIII, bajo la administración jesuita, los quesos de Tafí del Valle sentaron las bases de una identidad de producto de alta calidad, que lograron mantener a lo largo del tiempo. Fue el queso de gobernadores, diplomáticos y salones de alta sociedad.

Los primeros quesos se elaboraron a partir de la leche de vacas y ovejas que se criaban en la estancia local. Eran quesos curados, capaces de mantener su calidad a lo largo del tortuoso viaje cordillerano de veinte leguas, para llegar a la ciudad de Tucumán. Esta tradición, iniciada en el siglo XVIII bajo la administración de los jesuitas, se mantuvo en la centuria siguiente, cuando -tras visibilizarse en el Congreso de Tucumán-, fue apreciado por el cónsul general del Reino Unido en Buenos Aires y por el presidente Sarmiento, entre otros miembros de la élite regional. En el tercer cuarto del siglo XIX, el queso de Tafí del Valle mantenía intacta su identidad como queso curado; su elaboración demandaba mucho tiempo y, a pesar de las presiones del mercado, los maestros queseros se preocupaban para tomarse el tiempo necesario para alcanzar la calidad. Ni los reclamos del presidente de la República los hacía interrumpir el proceso para vender más rápido. En este tiempo, el queso de Tafí del Valle ya tenía dos variantes principales, una clásica y otra condimentada con ají.

El itinerario histórico del queso de Tafí del Valle se destaca por su excepcionalidad. Durante dos centurias fue el único queso relevante del cono sur de América, junto con el queso de Chanco, surgido en el siglo XVII en el secano costero e interior del Valle Central de Chile. Dentro del actual territorio argentino, el queso de Tafí del Valle fue un notable caso de liderazgo, al contrastar con la situación de la región. En efecto, la abundancia de ganado en el espacio rioplatense-pampeano, no generó una cultura de elaboración y apreciación del queso, como comentaron -con asombro- los viajeros británicos de comienzos del siglo XIX. Gran esfuerzo realizó Sarmiento para revertir esta situación mediante sus batallas periodísticas y culturales.

A fines del siglo XX, se comenzó a revalorizar este producto con promisorias iniciativas, como la casi cincuentenaria Fiesta del Queso. Los maestros queseros de Tafí del Valle tienen la responsabilidad de mantener una tradición de tres siglos.

\section{Agradecimientos}

El autor agradece al Proyecto Fondecyt 1130096 por el financiamiento realizado.

\section{Literatura Citada}

Acevedo, E.O.

1965. La intendencia de Salta del Tucumán en el Virreinato del Río de la Plata. UNC. Mendoza, Argentina, 533 pp.

Aguilera, $\mathrm{P}$.

2016. El queso de Chanco: un producto típico de la industria popular de Chile (Siglos XVIII y XIX). RIVAR, 3 (8): 41-63.
Balmaceda, D.

2016. La comida en la historia argentina. Sudamericana. Buenos Aires, Argentina, 310 pp.

Bazán, A.R.

1995. Historia del Noroeste Argentino. Plus Ultra Buenos Aires, Argentina, 434 pp. 
Beaumont. J.A.B.

1828. Travels in Buenos Ayres, and the adjacent provinces of the Rio de la Plata. (1826-1827). Brettell. London, Reino unido, $270 \mathrm{p}$.

Carrera, J.

2011. Algo más que mercachifles. Pulperos y pulperías en la campaña bonaerense 1770-1820. Prohistoria. Rosario, Argentina, $232 \mathrm{p}$.

Caldcleugh, A

1825. Travels in South America during the years 1819-20-21. Volumen 1. Murray. London, Reino Unido, 373 p.

Castro, A.; Pszczólkowski, P.; Mujica, F.; Lacoste, P.; Núñez,

E.; Cofré, C.; Adunka, M.L.; Soto, N.

2016. El pajarete de Huasco y Elqui (Chile). Historia de un vino escogido. Idesia, 34 (4): 1-12.

Castro, A.

2016. Chicha y Sidra de manzana en Chile (1870-1930): manzanas con identificación de origen. RIVAR, 3 (8): 4-25.

Cofré, C.; Núñez, E.; Mujica, F. y Lacoste, P.

2016. La guerra del Pisco a través de las etiquetas. Idesia, 34 (2): 25-32.

Furlong, G.

1994. Los jesuitas y la cultura rioplatense. Prólogo de Fernando Storni. Editorial Biblos /Secretaría de Cultura de la Nación. Buenos Aires, Argentina, 207 p.

Giberti, H.

1985 Historia económica de la ganadería argentina. Hyspamérica. Buenos Aires, Argentina, 275 p.

Head, F.B.

1826. Rough notes taken during me rapid journey's across the pampas and among the Andes. Murray. London, Reino Unido, $309 \mathrm{p}$.

Lacoste, P.; Soto, N. y Jiménez, D.

2014. Genesis and identity of Chanco cheese (Chile 17501860). Contribution to the study of Appellations of Origin in Latin America. Cien. Inv. Agr., 41 (3): 317-325.

Lacoste, P.; Castro, A.; Jiménez, D.; Soto, N.; Rendón, B. and Briones, $\mathrm{F}$.

2015. The rise and fall of Chanco cheese in Chile (18601930). Cien. Inv. Agr., 42 (1): 85-96.
Lacoste, $\mathrm{P}$.

2016. El pisco nació en Chile. Génesis de la primera Denominación de Origen de América. Editorial RIL. Santiago, Chile, 457 p.

Love, G.T.

2014 (1826). Cinco años en Buenos Aires 1820-1825. Claridad. Buenos Aires, Argentina, 141 p.

Maeder, E.

2000. La administración y destino de las temporalidades jesuíticas del Río de la Plata. Buenos Aires, Argentina, $282 \mathrm{p}$.

Maino, V.

1996. La navegación del Maule. Una vía de conexión con el exterior (1794-1898). Editorial Universidad de Talca. Talca, Chile, $273 \mathrm{p}$.

Mayo, C.

2000. Pulperos y pulperías de Buenos Aires (1740-1830). Biblos. Buenos Aires, Argentina, 139 p.

Montoya, A.

2012. Historia de los saladeros argentinos. Letemendia. Buenos Aires, Argentina, 220 p.

Parish, W.

1956. Buenos Aires y las provincias del Río de la Plata. Traducido del inglés al castellano y aumentado con notas y apuntes por Justo Maeso, Buenos Aires, Benito Hortelano. Hachette (Edición original 1852). Buenos Aires, Argentina, $654 \mathrm{p}$.

Peña de Bascary, S.

1986. Compañía de Jesús. Aporte para el estudio del acrecentamiento de propiedad en la provincia de Tucumán. Boletín Museo Casa Histórica de la Independencia, 3: 91-109.

Prestigiacomo, R.; Uccello, F.

2014. La pequeña aldea. Editorial EUDEBA. Buenos Aires, Argentina, $156 \mathrm{p}$.

Sarmiento, D.F.

2001. Obras completas. Universidad de La Matanza. Buenos Aires, Argentina. LIII tomos.

Silveira, M.

2005. Cocina y comidas en el Río de la Plata. Editorial Universidad del Comahue (EDUCO). Neuquén, Argentina, 192 p. 
